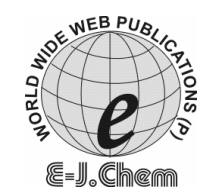

http://www.e-journals.net
ISSN: 0973-4945; CODEN ECJHAO

E-Journal of Chemistry

Vol. 5, No.4, pp. 872-877, October 2008

\title{
Effect of Withania Somnifera Root Powder on the Levels of Circulatory Lipid Peroxidation and Liver Marker Enzymes in Chronic Hyperammonemia
}

\author{
B. HARIKRISHNAN, P. SUBRAMANIAN* and S. SUBASH \\ Department of Biochemistry and Biotechnology, \\ Faculty of Science, Annamalai University, \\ Annamalainagar-608 002, Tamilnadu, India. \\ annamalai_rhythm@yahoo.co.in; Tel: +914144238343
}

Received 19 May 2008; Accepted 24 June 2008

\begin{abstract}
Withania somnifera (L) Dunal (Solanaceae), commonly called Ashwagandha (Sanskrit) is an Ayurvedic Indian medicinal plant, which has been widely used as a home remedy for several ailments. We have investigated the influence of W.somnifera root powder on the levels of circulatory ammonia, urea, lipid peroxidation products such as TBARS (thiobarbituric acid and reactive substances), HP (hydroperoxides) and liver marker enzymes such as AST (aspartate transaminase), ALT (alanine transaminase) and ALP (alkaline phosphatase), for its hepatoprotective effect in ammonium chloride induced hyperammonemia. Ammonium chloride treated rats showed a significant increase in the levels of circulatory ammonia, urea, AST, ALT, ALP, TBARS and HP. These changes were significantly decreased in rats treated with W.somnifera root powder and ammonium chloride. Our results indicate that W.somnifera offers hepatoprotection by influencing the levels of lipid peroxidation products and liver markers in experimental hyperammonemia and this could be due to (i) the presence of alkaloids, withanolids and flavonoids, (ii) normalizing the levels of urea and urea related compounds, (iii) its free radical scavenging property and (iv) its antioxidant property. The exact underlying mechanism is still unclear and further research needed.
\end{abstract}

Keywords: Withania somnifera, Hyperammonemia, Lipid peroxidation, Liver marker enzymes

\section{Introduction}

Hyperammonemia is a major contributing factor to neurological abnormalities observed in hepaticencephalopathy and in congenital defects of ammonia detoxication. Hyperammonemia 
is a heterogenous group of disorders characterized by elevated levels of ammonia, causing irritability, somnolence, vomiting, seizures and derangement of the cerebral function, coma and death ${ }^{1,2}$. Ammonia toxicity results in lipid peroxidation and free radical generation, which causes hepatic dysfunction and failure, significantly increases the number of brain peripheral benzodiazepine receptors and could also increase the affinity of ligands for these receptors that might enhance GABA adrenegergic neurotransmission. These changes probably contribute to deterioration of the intellectual function, decreased consciousness, coma and death $\mathrm{h}^{3-5}$. The increased entry of ammonia to the brain is a primary cause of neurological disorders associated with hyperammonemia, such as hepatic encephalopathies, Reye syndrome, several other metabolic disorders, and some toxicencephalopathies. A five to ten- fold increase in ammonia in the blood induces NMDA receptor mediated toxic effects in most animal species, with alterations in the function of the central nervous system ${ }^{5}$.

The greatest disadvantage in presently available potent synthetic antihyperammonemic agents/therapies lies in their toxicity and the reappearance of symptoms after discontinuation. Therefore, the screening and development of drugs for their antihyperammonemic activity is still in progress and there is much hope of finding antihyperammonemic drugs from indigenous medicinal plants. There is a need to search for appropriate protective agents against hyperammonemia without side effects. This search can be focused on plants used in traditional medicine and on natural products that may offer treatment for hyperammonemia than currently used drugs. Ashwagandha (Withania somnifera L. Dunal solanaceae) is an important medicinal plant, widely used as a home remedy for several diseases in India as well as other parts of the world ${ }^{6}$.

The chemical composition, pharmacological and therapeutic efficacy of this plant has been well established ${ }^{7}$. Different investigators reported that $W$. sommifera possess antiserotogenic, hyperlipidemia, parkinson's disease ${ }^{8}$, anticancer, anabolic activity and beneficial effects in the treatment of arthritis, geriatric problems ${ }^{9}$ and stress ${ }^{10}$. Further the plant has been reported to have anti-inflammatory, antitumour, antistress, antioxidant, immunomodulatory, hematopoietic and rejuvenating properties ${ }^{11,12}$. It is one of the most commonly used herbs, not only as an antistress and adaptogenic agent, but is also known to increase life span and delay ageing ${ }^{13}$. The roots of $W$. somnifera contain several alkaloids, withanolides, a few flavonoids and reducing sugars ${ }^{14}$ and are also rich in iron ${ }^{15}$. The major active compounds of the roots are reported to be withanolides, glycosides and many different alkaloids. To date, up to 19 withanolide derivatives ${ }^{16}$ have been isolated form Withania roots (Table 1).

However, despite the observation of diverse medicinal activities attributed to this plant, no biochemical studies have been carried out to shed light on the role of $W$. somnifera on hyperammonemia. In this context, the present study was undertaken to investigate the effect of root powder of $W$. somnifera on blood ammonia, plasma urea, TBARS (thiobarbituric acid and reactive substances), HP (hydroperoxides) and the liver marker enzymes sch as AST (aspartate transaminase), ALT (alanine transaminase) and ALP (alkaline phosphatase) in serum in control and ammonium chloride $\left(\mathrm{NH}_{4} \mathrm{Cl}\right)$ treated.

\section{Experimental}

\section{Chemicals}

Ammonium chloride was purchased from Sisco Research Laboratories, Mumbai, India. All other chemicals used in the study were of analytical grade. 
Table 1. Active compounds of Withania somnifera ${ }^{16}$

\begin{tabular}{|c|c|}
\hline S. No & Name \\
\hline 1 & Withaferin A \\
\hline 2 & Diacetylwithaferin A \\
\hline 3 & 2,3-Dihydrowithaferin A \\
\hline 4 & Withanolide viscosalactone B \\
\hline 5 & 27-o-B-D-Glucopvranosvl viscosalactone B \\
\hline 6 & Dihydrowithaferin A \\
\hline 7 & 27-o-Glucopyranosylwithaferin A \\
\hline 8 & Withanoside I-VII \\
\hline 9 & 24,25-Dihydro-27-desoxywithaferin A \\
\hline 10 & Physagulin $\mathrm{D}(1 \rightarrow 6)-\beta$-D-glucopvranosvl- $(1 \rightarrow 4)$ - $\beta$-D-glucopvranoside \\
\hline 11 & Sitoindosides VII-X \\
\hline 12 & 27- $o$-B-D-Glucopyranosylphysagulin D \\
\hline 13 & 5-Dehydroxywithanolide R \\
\hline 14 & Withasomniferin A \\
\hline 15 & 1-Oxo-5B.6B-epoxv-witha-2-ene-27-ethoxv-olide \\
\hline 16 & 4-(1-Hydroxy-2,2-dimethylcyclopropanone)-2,3-dihydrowithaferin A \\
\hline 17 & D-Glucopyranosyl \\
\hline 18 & D-Glucopyranoside \\
\hline 19 & 4,16-Dihydroxy- $5 \beta, 6 \beta$-epoxyphysagulin D \\
\hline
\end{tabular}

\section{Animals}

Adult male albino Wistar rats, weighing 180-200 g, bred in the Central Animal House, Rajah Muthiah Medical College, Annamalai University, were used. The animals were housed in polycarbonate cages in a room with a $12 \mathrm{~h}$ day-night cycle, temperature of $22 \pm 2^{\circ} \mathrm{C}$ and humidity of $45-64 \%$. During the whole experimental period, animals were fed with a balanced commercial diet (Hindustan Lever Ltd., Mumbai, India) and water and ad libitum. All animal experiments were approved by the ethical committee (vide No.355/2006, date: 18.10.2006), Annamalai University and were in accordance with the guidelines of the National Institute of Nutrition (NIN), Indian Council of Medical Research (IMCR), Hyderabad, India.

\section{Induction of experimental hyperammonemia}

Hyperammonemia was induced in Wistar rats by intraperitoneal injections of ammonium chloride at a dose of $100 \mathrm{mg} / \mathrm{kg}$ body weight thrice in a week for 8 consecutive weeks ${ }^{17}$.

\section{Experimental design}

In the experiment, a total number for 32 rats were used. The rats were divided into four groups of 8 rats each. Groups I rats were normal and untreated. Group II normal rats administered with $W$. somnifera $\left(500 \mathrm{mg} / \mathrm{kg}\right.$ body weight) using an intragastric tube ${ }^{18}$, group III rats treated with $\mathrm{NH}_{4} \mathrm{Cl}(100 \mathrm{mg} / \mathrm{kg}$ body weight; i.p $)$ and group IV rats treated with $\mathrm{NH}_{4} \mathrm{Cl}+W$. somnifera thrice in a week for 8 consecutive weeks. At the end of 8 weeks, the rats were kept overnight fasting and sacrificed by cervical dislocation after anaesthetizing the animal with intramuscular injection of ketamine hydrochloride $(30 \mathrm{mg} / \mathrm{kg}$ body weight). Blood samples were collected for various biochemical estimations such as blood ammonia ${ }^{19}$, plasma urea ${ }^{20}$, TBARS $^{21}, \mathrm{HP}^{22}$, serum AST and $\mathrm{ALT}^{23}$ and $\mathrm{ALP}^{24}$.

\section{Plant material}

The dried roots of $W$. somnifera were collected from Chidambaram, Cuddalore District, Tamil Nadu, India. The root was identified and authenticated at the Herbarium of Botany Directorate in Annamalai University. A voucher specimen (No: 2934) was deposited in the Botany Department of Annamalai University. 


\section{Preparation of withania somnifera extract}

The roots were thoroughly washed with $95 \%$ ethanol and with sterile water. They were air dried and powdered its aqueous suspension in $2 \%$ gum acacia was used at a dose of $500 \mathrm{mg} / \mathrm{kg}$ body weight ${ }^{25}$.

\section{Statistical analysis}

Statistical analysis was performed using one-way analysis of variance (ANOVA) followed by Duncan's multiple range test (DMRT) using SPSS software package 9.05. Results were expressed as mean \pm SD from 8 rats in each group $p$ values $<0.05$ were considered as significant.

\section{Results}

The levels of circulatory ammonia, urea, TBARS, HP, AST, ALT and ALP increased significantly in ammonium chloride treated rats (Table 2). Ammonium chloride and $W$. somnifera treated rats showed significantly low levels of circulatory ammonia, urea, TBARS, HP, AST, ALT and ALP when compared with the corresponding ammonium chloride group (Table 2). Rats treated with W. somnifera alone showed no significant differences in levels of ammonia, urea, TBARS, HP, AST, ALT and ALP when compared with control rats (Table 2).

\section{Discussion and Conclusion}

In the liver, ammonia is removed either in the form of urea in periportal hepatocytes and/or as glutamine in perivenous hepatocytes ${ }^{26}$. Increased levels of circulatory ammonia and urea might indicate an hyperammonemic condition in the rats treated with ammonium chloride ${ }^{2,4}$. Increased levels of circulatory TBARS, HP, AST, ALT and ALP may be due to the liver damage caused by ammonia-induced free radical generation. Reports have shown that excess ammonia induces nitric oxide synthase, leading to enhanced production of nitric oxide, which in turn leads to oxidative stress and liver damage ${ }^{27,28}$. Decreased levels of circulatory ammonia, urea, TBARS, HP, AST, ALT and ALP in group IV rats may be due to the antioxidant potential of $W$. somnifera and it was reported that plants products, phenolic compounds and flavonoids have the ability to remove excess ammonia, urea, uric acid, nonprotein nitrogen and creatinine and offer protection against hyperammonemic and nephrotoxic conditions ${ }^{29}$ and this plant has antioxidant, antiperoxidative and free radical quenching posterities in various diseased conditions $\mathrm{s}^{30}$.

A relationship between oxidative stress and hyperammonemia has been well established and evidence indicates that ammonium (acetate/chloride) salts induce hyperammonemia partly via oxidative stress $^{2-4}$. Flavanoids and polyphenolic compounds are potent free radical scavengers and are known to modulate the activities of various enzyme systems due to their interaction with various biomolecules ${ }^{31}$. The roots of $W$. somnifera contain severalalkaloids, withanolides, a few flavonoids and reducing sugars ${ }^{32}$. The active compounds reported in $W$. somnifera include withaferin A, 1-oxo-5 $\beta$, 6 $\beta$-epoxy-witha-2-ene-27-etnoxy-olide, etc, ${ }^{32,33}$. These reports suggest that Withania is a rich source of bioactive compounds ${ }^{16}$. Phytochemicals are well known potent free radical scavengers and it has also been reported that the root extract of $W$. somnifera tends to reverse the changes in lipid peroxidation and damage to cells ${ }^{7}$. Hence, the mechanism by which the $W$. somnifera exerts a hepatoprotective effect in a hyperammonemic condition could be attributed to (i) presence of natural antioxidants, (ii) its free radical scavenging and antioxidant properties and (iii) excess removal of urea related compounds. The exact underlying mechanism is still unclear and further research is needed. 
Table 2. Effect of $W$. somnifera on changes in the blood ammonia, plasma urea, TBARS, HP, serum AST, ALT and ALP of control and treated rats

\begin{tabular}{|c|c|c|c|c|c|c|c|}
\hline Groups & $\begin{array}{c}\text { Blood } \\
\text { ammonia, } \\
\mu \mathrm{mol} / \mathrm{L}\end{array}$ & $\begin{array}{l}\text { Blood Urea, } \\
\text { mg/dL }\end{array}$ & $\begin{array}{l}\text { TBARS, } \\
\mathrm{nmol} / \mathrm{mL}\end{array}$ & $\begin{array}{l}\mathrm{HP} \times 10^{-5} \\
\mathrm{mmol} / \mathrm{dL}\end{array}$ & AST, IU/L & ALT, IU/L & ALP, IU/L \\
\hline Control & $98.88 \pm 6.98^{a}$ & $11.34 \pm 1.20^{\mathrm{a}}$ & $1.58 \pm 0.12^{\mathrm{a}}$ & $8.51 \pm 0.65^{\mathrm{a}}$ & $72.54 \pm 5.55^{\mathrm{a}}$ & $26.18 \pm 2.00^{\mathrm{a}}$ & $76.54 \pm 5.66^{\mathrm{a}}$ \\
\hline $\begin{array}{l}\text { Control+ W.S } \\
(500 \mathrm{mg} / \mathrm{kg})\end{array}$ & $88.91 \pm 6.08^{\mathrm{a}}$ & $11.48 \pm 1.17^{\mathrm{a}}$ & $1.55 \pm 0.11^{\mathrm{a}}$ & $8.12 \pm 0.62^{\mathrm{a}}$ & $69 . .60 \pm 5.31^{\mathrm{a}}$ & $23.92 \pm 1.82^{\mathrm{a}}$ & $75.55 \pm 5.63^{\mathrm{a}}$ \\
\hline $\begin{array}{l}\mathrm{NH}_{4} \mathrm{Cl} \\
(100 \mathrm{mg} / \mathrm{kg})\end{array}$ & $540.85 \pm 59.5^{\mathrm{b}}$ & $24.15 \pm 5.60^{\mathrm{b}}$ & $3.09 \pm 0.23^{\mathrm{b}}$ & $15.01 \pm 1.00^{\mathrm{b}}$ & $115.26 \pm 8.80^{\mathrm{b}}$ & $60.54 \pm 4.65^{\mathrm{b}}$ & $159.55 \pm 10.65^{b}$ \\
\hline $\begin{array}{l}W . S(500 \mathrm{mg} / \mathrm{kg})+ \\
\mathrm{NH}_{4} \mathrm{Cl}(100 \mathrm{mg} / \mathrm{kg})\end{array}$ & $148.16 \pm 26^{c}$ & $15.25 \pm 0.76^{\mathrm{c}}$ & $1.09 \pm 0.23^{\mathrm{c}}$ & $9.81 \pm 0.74^{\mathrm{c}}$ & $83.53 \pm 6.38^{\mathrm{c}}$ & $30.22 \pm 2.3^{c}$ & $88.36 \pm 6.78^{c}$ \\
\hline
\end{tabular}

Data are presented as means \pm SD of 8 rats in each group.

The values with different superscript $(\mathrm{a}, \mathrm{b}, \mathrm{c})$ are significant from each others, $\mathrm{P}<0.05$ mean values are significantly different from the other groups (ANOVA followed by DMRT). 


\section{Acknowledgement}

B. Harikrishnan, gratefully acknowledges the financial assistance in the form of "Research Student Fellowship" from Annamalai University.

\section{References}

1. Murthy C R, Rama Rao K V, Bai G and Norenburg M D, J Neurosci Res., 2001, 66, 282.

2. Essa M M and Subramanian P, Fund Clin Pharmacol., 2006, 3, 299.

3. Kosenko E, Kaminsky A, Valencia M, Lee L, Hermenegildo C and Felipo V, Free Radic Res., 1997, 27, 637.

4. Lena P J and Subramanian P, Pharmazie, 2004, 59, 636.

5. Majeed K I, E Med J, 2005, 2, 12.

6. Owais M, Sharad K S, Shehbaz A and Saleemuddin M, Phytomedicine, 2005, 12, 229.

7. Dhuley J N, J.Ethnopharmacol., 2000, 70, 57

8. Gupta G L and Rana A C, Pharmacology Reviews., 2007, 1, 129.

9. Asthana R and Raina M K, Indian Drugs., 1989, 26, 199.

10. Grandhi A, Mujumdar A and Patwardhan B. J. Ethnopharmacol. 1994, 44, 131.

11. Gautam M, Diwanay S S, Gairola S, Shinde Y S, Jadhav S S and Patwardhan B K, Int. Immunopharmacol, 2004, 4, 841.

12. Rasool M and Varalakshmi P, Vascular Pharmacology, 2006, 44, 406.

13. Bhatnagar M, Jain C P and Sisodia S S, Cell Tissue Res., 2005, 5, 287.

14. Ganzera M, Choudhary M I and Khan I A, Fitoterapia, 2003, 74, 68.

15. Mishra L C, Singh B B and Dagenais S, Altern Med Rev., 2000, 5, 334.

16. Padmavathi B, Rath P C and Singh R P, Evid Based Complement Altemat Med., 2005, 2, 99.

17. Subash S, Subramanian P and Sivaperumal R, Cell Tissue Res., 2007, 7, 1043.

18. Khanam S and Devi K, Pharmacognosy Magazine, 2005, 1, 97.

19. Wolheim D F, Clin. Chern., 1984, 30, 906.

20. Varley H, Gowenlock A H and Bell M, Practical Clinical Biochemistry, $4^{\text {th }}$ Ed., CBS Publishers: New Delhi, 1998.

21. Niehaus WG and Samuelsson B, Eur J Biochem., 1968, 17, 126.

22. Jiang Z Y, Hunt J V and Wolff S P, Anal Biochem., 1992, 202, 384.

23. Reitman S and Frankel A S, Am J Clin Pathol., 1957, 28, 56.

24. King E and Armstrong A R, Canad Med Assoc J, 1934, 31, 376.

25. Rasool M and Varalakshmi P, Vascular Pharmacology, 2006, 44, 406.

26. Nelson D L and Cox M M, Lehninger Principles of Biochemistry. Macmillan: London, 2000.

27. Kosenko E, Kaminsky Y, Stavroskaya I G and Felipo V, Brain Res., 2000, 880, 139.

28. Schliess F, Gorg B, Fischer R, Desjardins P, Bidmon H J, Herrmann A, Butterworth R F, Zilles K and Haussinger D, FASEB J, 2002, 16, 739.

29. Davis L and Kuttan G, Cancer Lett., 2000, 148, 9.

30. Ahmad M, Saleem S and Ahmad A S, Hum Exp Toxicol., 2005, 24, 137.

31. Devipriya S and Shyamaladevi C S, Ind J Pharmacol, 1999, 31, 422.

32. Jayaprakasam B, Zhang Y, Seeram N P and Nair M G, Life Sci., 2003, 74, 125.

33. Kaur P, Sharma M, Mathur S, Manisha T, Divekar H M., Kumar R, Srivastava K K, Chandra R. The Journal of Alternative and Complementary Medicine., 2003, 9, 897. 


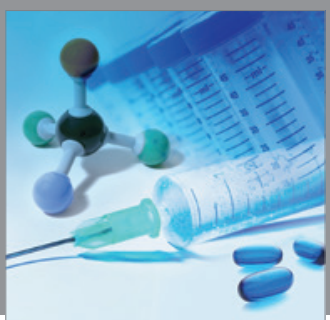

International Journal of

Medicinal Chemistry

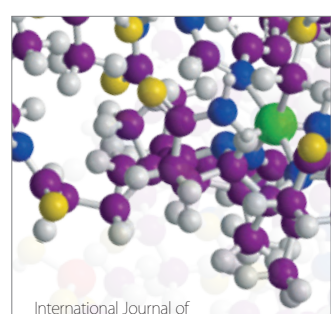

Carbohydrate Chemistry

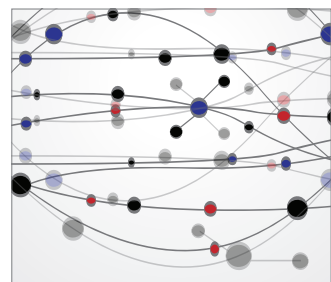

The Scientific World Journal
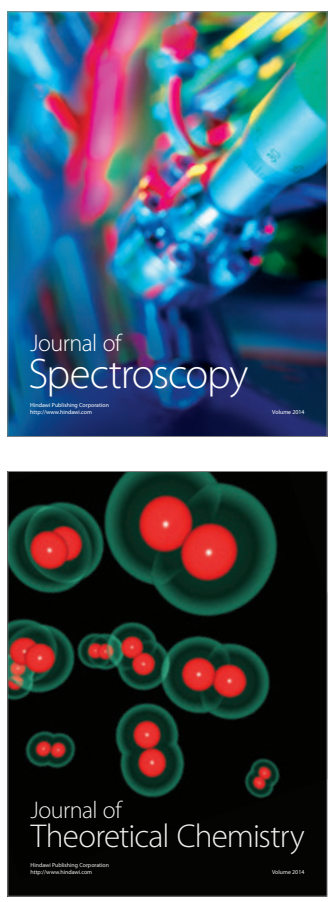
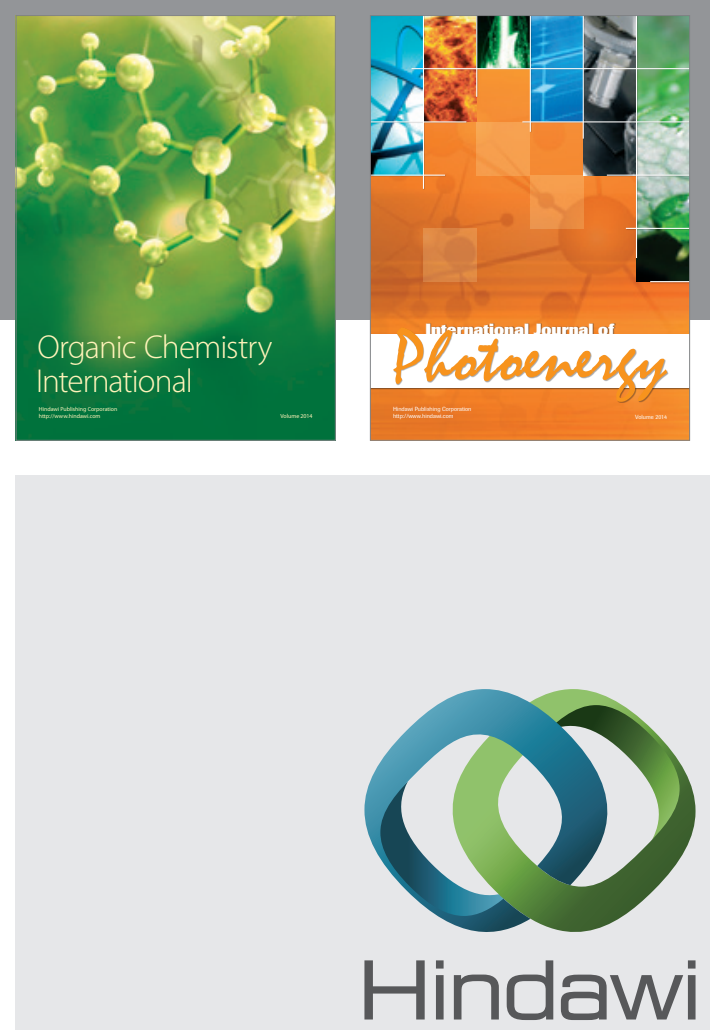

Submit your manuscripts at

http://www.hindawi.com
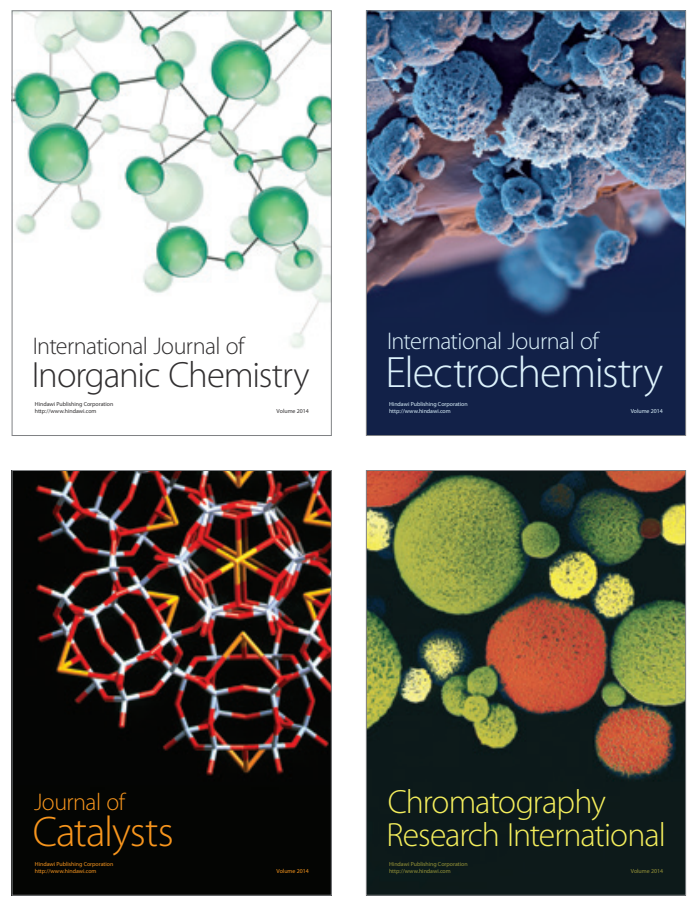
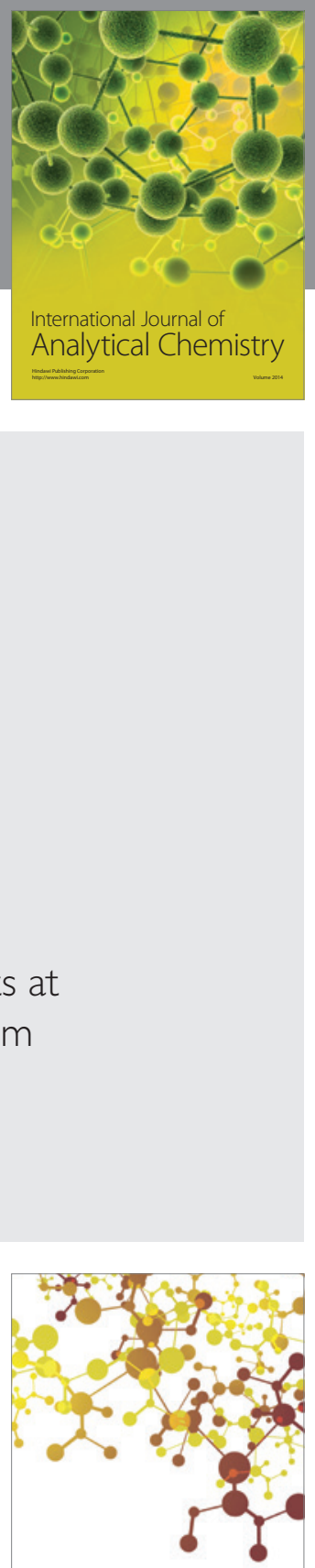

Journal of

Applied Chemistry
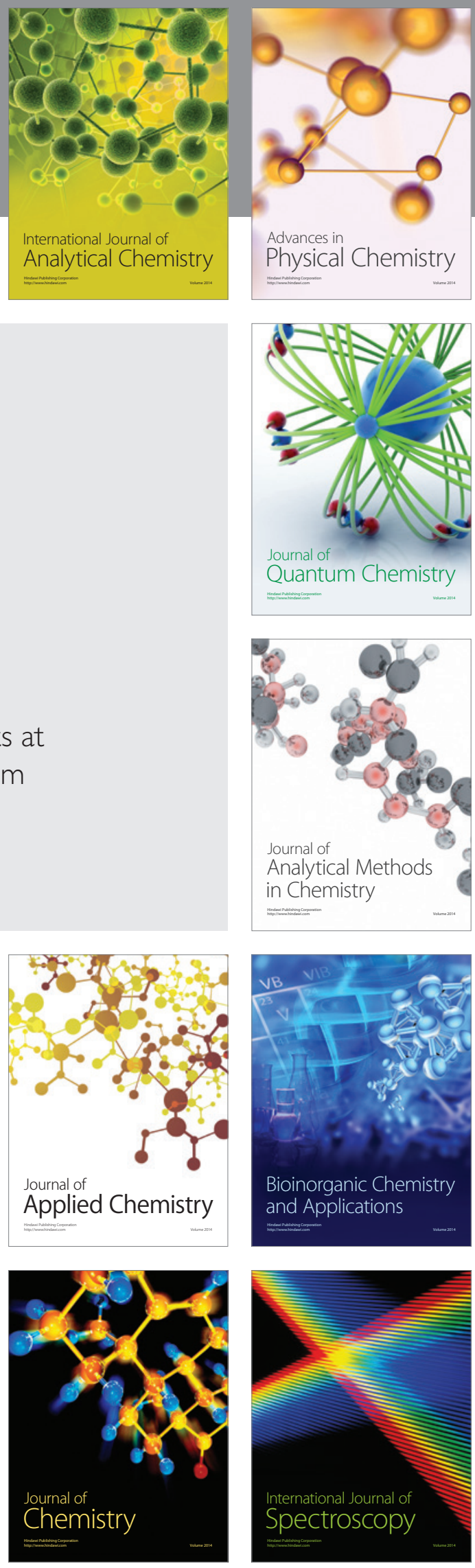